\title{
Why Oregon Patients Request Assisted Death: Family Members' Views
}

\author{
Linda Ganzini, MD, MPH', Elizabeth R. Goy ${ }^{1,2}$, and Steven K. Dobscha, $M D^{1,2}$
}

${ }^{1}$ Columbia Center for the Study of Chronic, Comorbid Mental and Physical Disorders, Health Services Research and Development, Research Service (R\&D 66), Portland VAMC, Portland, OR, USA; ${ }^{2}$ Department of Psychiatry, Oregon Health \& Science University, Portland, OR, USA.

J Gen Intern Med 23(8):1296

DOI: $10.1007 / \mathrm{s} 11606-008-0542-z$

(c) Society of General Internal Medicine 2008

In this article, the authors incorrectly cited the advocacy organization, "Compassion and Choices". The correct name of the advocacy organization that the authors intended is "Compassion and Choices of Oregon."

In addition, they incorrectly cited the URL of the national parent organization http://www.compassionandchoices.org) instead of URL the local organization http://www.compassio noforegon.org) that should have been cited instead.

The authors regret these errors.

The online version of the original article can be found at http://dx.doi. org/10.1007/s11606-007-0476-x.

Published online March 8, 2008 